\title{
The oxidative damage of Bisphenol $A$ on the organs of the mice
}

\author{
Chenjuan Ke, Xudong Liu, Haoxiao Zuo, Jingyun Zhao, Xu Yang, Junlin Yuan"
}

Central China Normal University, Hubei Key Laboratory of Genetic Regulation and Integrative Biology College of Life Science, Wuhan, China; ${ }^{\#}$ Corresponding Author: yuanjl@mail.ccnu.edu.cn

Received 8 May 2013; revised 9 June 2013; accepted 30 June 2013

Copyright (C) 2013 Chenjuan Ke et al. This is an open access article distributed under the Creative Commons Attribution License, which permits unrestricted use, distribution, and reproduction in any medium, provided the original work is properly cited.

\begin{abstract}
Bisphenol A (BPA) was used in the plastic industry and widely distributed in the environment, which might cause adverse effects to living organisms. In order to study the effects of BPA on the organs of mice brain, liver and testical, the $\mathrm{KM}$ mice were administrated to different concentrations of BPA $(0,0.09,0.9,9 \mathrm{mg} / \mathrm{kg} \cdot \mathrm{d})$. After 14 days, the reactive oxygen species (ROS), malondialdehyde (MDA) and glutathione (GSH) concentrations in the three organs were measured. Results showed that the ROS and MDA contents were increased with the added concentration of the BPA. But the GSH content was decreased. It is indicated BPA can induce the mice's oxidative damage and the effect is much easier for the brain.
\end{abstract}

Keywords: BPA; Kunming Mice; ROS; MDA; GSH; Oxidative Damage

\section{INTRODUCTION}

For more than ten years, there has been a scientific and journalistic controversy whether BPA causes adverse effects on human [1-3].

BPA (2, 2-bis(4-hydroxypheny) propane), which was first synthesized in 1891 and the first epoxy resins were developed until the early 1950s [4], is an environment contaminant, used as a monomer material for the production of resins and polycarbonate plastics. Exposure to BPA is widespread because of its use in a wide variety of consumer products. A major use of the BPA is in the making of clear, shatter resistant plastic, and as a coating for cans containing various food and also found in water bottles, baby bottles, food containers and some dental

${ }^{*}$ This work was financially supported by a grant from the Key Project of National Natural Science Foundation (51076079). fillings [5]. As a result of increased use of products based on epoxy resins and polycarbonate plastics, human exposure to BPA has increased [6]. It has been reported that BPA is leached from food and beverage containers, and some dental sealants and composites under normal conditions of use $[7,8]$.

Studies of possible health effects of BPA exposure on humans are limited. In humans, BPA levels in blood have been found to be associated with metabolic disorders including Type 2 diabetes and obesity, abnormal liver functions, prostate and breast cancer, endometrial hyperplasia, recurrent miscarriages, polycystic ovarian syndrome, and neurobehavioral problems such as attention deficit hyperactivity disorders and development effects in humans. In animals' studies, exposure of BPA has been reported to decrease the motility and count of sperms [9], and to stimulate the release of prolactin hormone [10].

Therefore, the aims of this study were to illustrate the effects of BPA on the acute oxidative damage and speculate the possible mechanism, by detecting the activity of relative fluorescence, the contents of MDA, and the contents of GSH.

\section{MATERIALS AND METHODS}

\subsection{Main Reagents and Equipments}

BPA (99.9\%) was purchased from the company of sigma. All other chemicals were of analytical grade. Low-temperature refrigerated centigrade (Eppendorf 5417R Germany). Sonicator and fluorescent micro plate spectrophotometer (B70-teck) were used in the experiments.

\subsection{Animals}

Albine male mice of SPF Kunming strain weighing 20 $22 \mathrm{~g}$ were used for the study. They were purchased from the center for Laboratory Animal Administration, 
Center for Disease Control and Prevention of Hubei Province (Wuhan, China). The experiments were conducted in experimental holding facility. All animals were kept under controlled environment condition (temperature: $23^{\circ} \mathrm{C} \pm 2{ }^{\circ} \mathrm{C}$, relative humidity of $50 \%-55 \%$ and with nature light) and hygienic conditions in polypropylene cages. Animals were allowed standard pellet diet and water libitum for the whole duration of the experiment. The animals were brought to laboratory at 3 days before the commencement of experiments for acclimatization to laboratory condition. Then through adopting a method of randomly arranging number, 36 mice were divided into 4 testing groups $(n=9$ each $)$.

\subsection{Exposure Conditions}

BPA was dissolved in soya-bean oil (vehicle for BPA) at a concentration of $0 \mathrm{mg} / \mathrm{ml}, 0.009 \mathrm{mg} / \mathrm{ml}, 0.09 \mathrm{mg} / \mathrm{ml}$, $0.9 \mathrm{mg} / \mathrm{ml}$. BPA exposure groups were given intragastrically with designed concentrations $(0.09 \mathrm{mg} / \mathrm{kg}, 0.9$ $\mathrm{mg} / \mathrm{kg}, 9 \mathrm{mg} / \mathrm{kg}$ ) for 14 days via a metal gastric-tube. To reduce physiological differences, control group was administered only soya-bean oil. The time of gastriclavage was from 8:00 - 9:00 every day.

\subsection{Tissue Sample Preparation}

Mice after administered in the second day of the stomach were killed by being pulled off the neck. Their brains, livers and testis were rapidly excised on a Petri dish placed dish placed on ice, rinsed and washed in icecold normal saline. Then they were weighed in the completely automatic electronic balance and then homogenized in ice-cold $0.9 \%$ (quality score) Nacl to produce 1:9 homogenates. Homogenates were centrifuged at 10,000 rpm for 10 minutes at $4^{\circ} \mathrm{C}$. The supernatant was collected and frozen at $-20^{\circ} \mathrm{C}$ for assessment of ROS, MDA and GSH.

\subsubsection{Reactive Oxygen Species (ROS) Contents Assay}

DCFH-DA, the non-light-emitting dye, could change into DCFH through discarding triacetate captured by intracellular esterase. Then DCFH would be oxidized by intracellular ROS and changed to 2, 7-dichlorofluorescein (DCF), emitting fluorescence. So according this theory, we can take the following steps to measure ROS [11].

At first, $2 \mu \mathrm{L}$ of sample solution was removed to the test tube, and $198 \mu \mathrm{L}$ (for brain and testis supernatant) and $398 \mu \mathrm{L}$ (for liver supernatant) of normal saline was added. And then, $100 \mu \mathrm{L}$ of the mixture sample solution was removed to the 96-well micro plate, and $100 \mathrm{~L}$ DCFH-DA fluorescent dyestuff, which 1000 multiple diluted by PBS $(\mathrm{pH}=7.5)$. The visual image of ROS generation in cells was made using a fluorescent micro plate spectrophotometer with an excitation of $485 \mathrm{~nm}$ and an emission of $525 \mathrm{~nm}$.

\subsubsection{Malondialdehyde Contends (MDA) Assay}

$0.5 \mathrm{~mL}$ sample dilution was removed to the test tube, and $2 \mathrm{ml}$ of $0.6 \%$ TBA solution was added. TBA solution was dissolved by a small amount of $1 \mathrm{~mol} / \mathrm{L}$ sodium hyroxide, and then diluted to the concentration by $10 \%$ trichloroacetic acid. The test tube was sealed by plastic wrap with a little hole. After in the water bath boiling for 15 minutes, the test tube was cooled in the water, and then centrifuged at $10,000 \mathrm{rpm}$ for 10 minutes. The absorbance value of the supernatant was measured at 450 $\mathrm{nm}, 532 \mathrm{~nm}$ and $600 \mathrm{~nm}$ of wavelength. The formula $\mathrm{C}=$ $6.45 \times\left(D_{532}-D_{600}\right)-0.56 \times D_{450}$ was used to calculated the concentration of MDA.

\subsubsection{Glutathione (GSH) Contents Assay}

Low molecular weight thiols (predominantly GSH) in cells were examined using Multiskan Spectrum, which produces a highly absorbance at $412 \mathrm{~nm}$ upon its reaction with thiols groups. $200 \mu \mathrm{L}$ of the supernatant was took and mingled with $50 \mu \mathrm{L}$ of $10 \%$ TCA, so that the protein was precipitated, then centrifuged the liquid for the second time so as to eliminate the protein. The supernatant was diluted with PBS-EDTA, regulated $\mathrm{pH}$ with sodium hydroxide to 7.5 , and then $50 \mu \mathrm{L}$ sample solution and $150 \mu \mathrm{L}$ DTNB of $60 \mu \mathrm{g} / \mathrm{mL}$ were joined into 96 wells micro plate, kept in dark place for 5 minutes at room temperature. Finally detected the OD values at the wavelength of $412 \mathrm{~nm}$, calculate the concentration of GSH according to the standard curve.

\subsection{Statistical Analysis}

The differences between treated samples and untreated control were evaluated by the students' T-test following a one-way analysis of variance (ANOVA). The level for a significant difference was set $p<0.05$ and $p<0.01$ meat very significant differences by the Origin 6.0.

\section{RESULTS}

\subsection{The Content of ROS}

Results of the levels of ROS after administration with BPA were showed in Figure 1. As showed in Figure 1, compared with the control group, the increase levels of ROS of $0.09 \mathrm{mg} / \mathrm{kg} \cdot \mathrm{d}$ BPA concentration exposure was not significant difference $(p>0.05)$, with the exposure concentration increased to $0.9 \mathrm{mg} / \mathrm{kg} \cdot \mathrm{d}$ and $9 \mathrm{mg} / \mathrm{kg} \cdot \mathrm{d}$, the increase of ROS levels were significantly different $(p<$ 0.05 or $p<0.01)$ for all the three organs. At the same time, it also demonstrated a certain degree of dose-dependent relationship. 


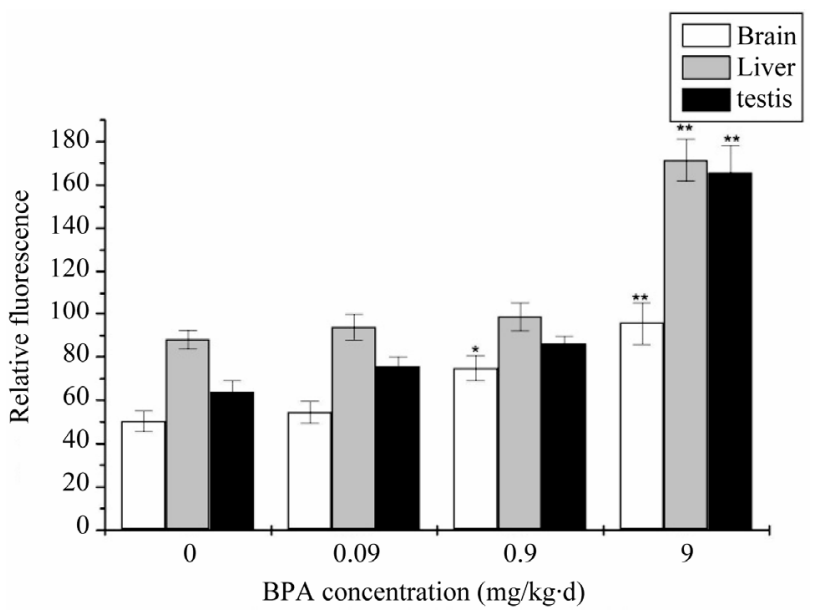

Figure 1. The change of concentration of Malondialdehyde (ROS) after administration by BPA (Compared with the control group, $*: p<0.05, * *: p<0.01)$.

\subsection{The Content of MDA}

The MDA levels of all exposure groups were significantly increased compared with the control group. The result of the contents of MDA was showed in Figure 2. Compared with the control group, a dramatic and dosedependent elevation of MDA contents was observed in each group. It was significantly increased in $0.9 \mathrm{mg} / \mathrm{kg} \cdot \mathrm{d}$ and very significantly increased in $9 \mathrm{mg} / \mathrm{kg} \cdot \mathrm{d}$ for the brain. While for the liver and testis, it was very significantly increased in $9 \mathrm{mg} / \mathrm{kg} \cdot \mathrm{d}$.

\subsection{The Content of GSH}

GSH content of mouse organs in different concentration of BPA group was shown in Figure 3. Compared with the control group, BPA did not decreased to the GSH content at the beginning and no significantly stimulative effect was noticed. However, it was significantly decreased in $0.9 \mathrm{mg} / \mathrm{kg} \cdot \mathrm{d}$ and very significantly decreased in $9 \mathrm{mg} / \mathrm{kg} \cdot \mathrm{d}$ for the brain. It did not appear the very significantly decreased until the BPA concentration upped to $9 \mathrm{mg} / \mathrm{kg} \cdot \mathrm{d}$ for the liver and testis proved degree of dose-dependent relationship.

\section{CONCLUTIONS}

Oxidative stress has been defined as a disturbance in the pro-oxidative-antioxidant balance in favor of the former, leading to potential damage [12]. The research before showed that ROS may be one of the major mediators in the regulation of autophagy [13], ROS is a natural byproduct of the normal metabolism in cells. A certain amount of ROS could function as a second message in the signal transduction of healthy cells. However, excessive ROS damages bimolecular, triggers the apoptosis pathways, and even further induces cell death, ex-

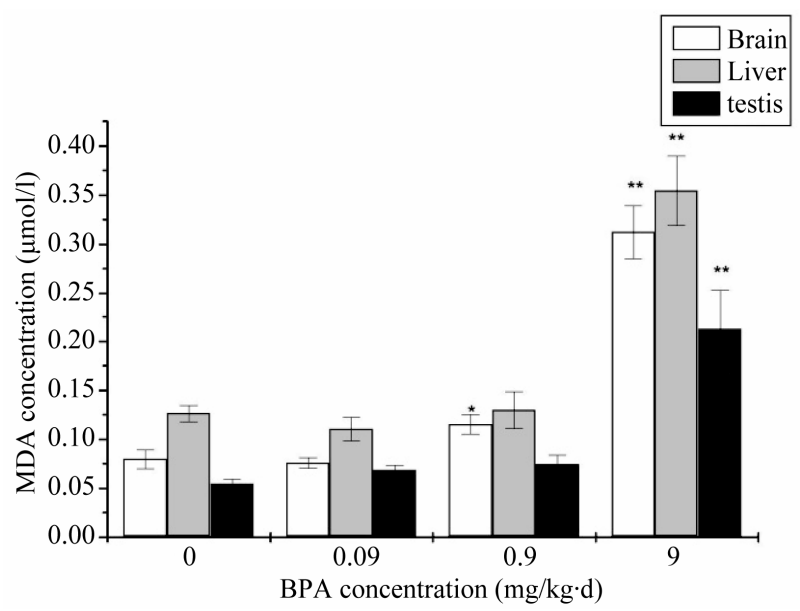

Figure 2. The change of concentration of Malondialdehyde (MDA) after administration by BPA (Compared with the control group, $*: p<0.05, * *: p<0.01)$.

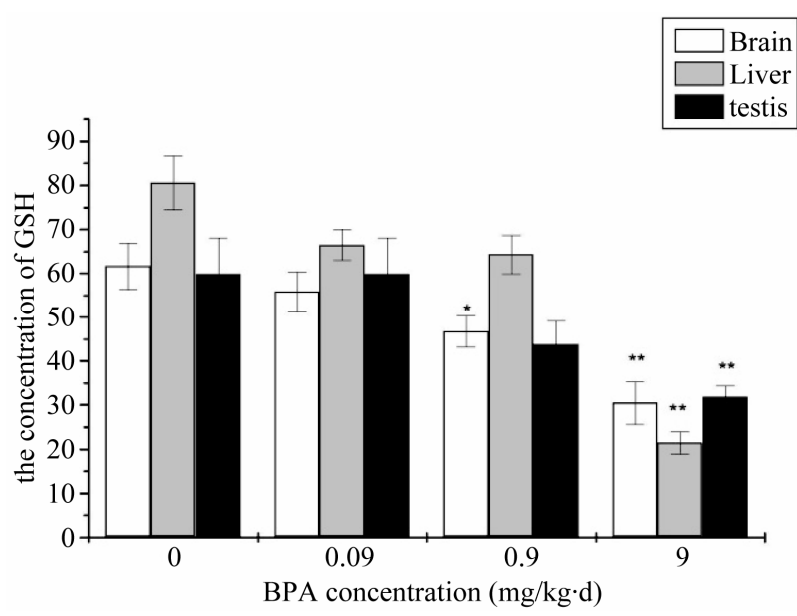

Figure 3. The change of concentration of Malondialdehyde (GSH) after administration by BPA (Compared with the control group, *: $p<0.05, * *: p<0.01)$.

cessive ROS and oxidative stress may be the main reasons for multiple toxicities [14]. In the present study, we also found that ROS generation in this three organs of BPA treatment groups increased significantly compared with the control group. At the same time, excess ROS can also damage a wide variety of cellular constituents including DNA, RNA, Proteins, sugar and lipids, thereby compromising cell viability. The result of Figure $\mathbf{1}$ is similarly with others who demonstrated that BPA can generate ROS that causes oxidative damage in the brain, reproductive tract, and liver of rats [15-17].

Typically, lipid peroxidation (LPO) was the primary results of oxidative stress, and correlated effects on the levels of MDA were also observed.

It's known that free radicals, including ROSs, remove electrons from lipid membrane, leading to a chain of reactions called "lipid peroxidation" [18]. MDA is the 
peroxidation metabolite, the content changes can reflect the degree of LPO in the organism. The toxicity of MDA is so great that it can induce the peptide chain's fracture and cross-linking of amino acids in enzyme molecule to form the polymer. As a result, the enzyme activity is renewed, lost or changed, the structure of cell membrane is being destroyed, disorderly ionic exchange is induced inside and outside of cell membrane and excessive free radicals are produced. Then cells are destroyed and the organism is also injured. The result is agreed with the ROS result.

Besides, the balance of oxidants and antioxidants is very important for healthy cells. So the intracellular GSH level in the BPA treaded cells was monitored to further prove the formation of ROS. GSH is an important antioxidant that protects cells from ROS and plays a critical role in the intracellular ROS removal. Hence the depletion of intracellular GSH is usually regarded as a scientific measure of the oxidative stress. Just as illustrated in the Figure 3, the absorbance in the BPA treated cells was much weaker than the control group. In concordance with our results, Wu et al. showed significant decrease in the levels of GSH in BPA group; this decrease indicated tissues being damaged [19]. At the same time the results manifested a close-effect relationship between the GSH level and the BPA concentration.

From the figures, we can clearly get the oxidative damage of the brain seriously compared with the liver and the testicle at the BPA concentration of $0.9 \mathrm{mg} / \mathrm{kg} \cdot \mathrm{d}$. It is significantly than the control group. But they all show very significantly at the BPA concentration of 9 $\mathrm{mg} / \mathrm{kg} \cdot d$. D. G. Stump et al. used different BPA doses and confirmed similar pervious findings [20]. BPA can have effect on the organs such as liver, brain and so on at the higher doses. BPA can be dispersed to the organs of the body after administrated. It can also get to the brain. The brain consumes a large quantity of oxygen, making it particularly susceptible to oxidative stress [21]. The mice selected were in the time of growing development especially for the brain. Liver is a tissue which can detoxicate. To the testicle, it is an organ that can be effected only in the time of long BPA effect. The reason why the brain gets oxidative damage seriously may be here.

This paper researched the oxidative damage of BPA on the organs of the mice. Therefore, our study confirmed that the exposure to high concentrations of BPA causes oxidative stress by disturbing the balance between ROS and antioxidant defenses system in the organs of the mice [15]. Based on the experimental results, we can draw a conclusion that BPA shows potential acute, shortterm toxicity $[20,22]$, but it was a relative safe material under the low dose for the mouse. Currently, we should pay attention to the application damage, as the $0.9 \mathrm{mg} / \mathrm{kg} \cdot \mathrm{d}$ BPA administrated can induce oxidative damage espe- cially for the brain.

\section{REFERENCES}

[1] Borrell, B. (2010) Toxicology: The big test for Bisphenol A. Nature, 464, 1122-1124. doi:10.1038/4641122a

[2] Aschberger, K., Castello, P., Hoekstra, E., et al. (2010) Bisphenol A and baby bottles: Challenges and perspectives. JRC Scientific and Technical Reports, European Union.

[3] Taylor, J.A., vom Saal, F.S., Welshons, W.V., et al. (2010) Similarity of Bisphenol A pharmacokineticsin rhesus monkeys and mice: Relevance for human exposure. Environmental Health Perspectives, 9, 43-45.

[4] Vogel, S.A. (2009) The politics of plastics: The making and unmaking of Bisphenol A "safety". Public Health, 99, 559-566.

[5] Calafat, A.M., Ye, X., Wong, L.Y., et al. (2008) Exposure of the US population to Bisphenol A and 4-tertiaryoctylphenol. Environmental Health Perspectives, 116, 3944. doi:10.1289/ehp. 10753

[6] Takahashi, O. and Oishi, S. (2000) Disposition of orally administered 2,2-bis(4-hydroxyphenyl) propane (Bisphenol A) in pregnant rats and the placental transfer to fetuses. Environmental Health Perspectives, 108, 931-935. doi:10.1289/ehp.00108931

[7] Howe, S.R. and Borodinsky, L. (1998) Potential exposure to Bisphenol A from food contact use of polycarbonate resins. Food Additives and Contaminants, 15, 370-375. doi: $10.1080 / 02652039809374653$

[8] Yamamoto, T. and Yasuhara, A. (1999) Quantities of Bisphenol A leached from plastic waste samples. Chemosphere, 38, 2569-2576.

doi:10.1016/S0045-6535(98)00464-0

[9] Chitra, K.C., Sujatha, R. and Latchoumycandanem, C. (2001) Effect of lindane on antioxidant enzymes in epididymis and epididymal sperm of adult rats. Asian Journal of Andrology, 3, 205-208.

[10] Steinmetz, R., Brown, N.G. and Allen, D.L. (1997) The environmental estrogen Bisphenol A stimulates prolactin release in vitro and in vivo. Endocrinology, 138, 17801786. doi:10.1210/en.138.5.1780

[11] Zhitkovich, A. and Costa, M.A. (1992) Sensitive assay to detect DNA-protein crosslinks in intact cells and in vivo. Carcinogenesis, 13, 1485-1489.

[12] Sies, H. (1991) Oxidative stress from basic research to clinical application. The American Journal of Medicine, $\mathbf{9}$, 31-38. doi:10.1016/0002-9343(91)90281-2

[13] Wang, S.H., Shih, Y.L., et al. (2009) Cadmium toxicity toward autophagy through ROS-activated GSK-3beta in mesangial cells. Toxicological Sciences, 108, 124-131. doi:10.1093/toxsci/kfn266

[14] Nel, A., Xia, T., Madler, L., et al. (2006) Toxic potential of materials at the nanolevel. Science, 2, 622-627. doi:10.1126/science.1114397

[15] Korkmaz, A., Ahbab, M.A., Kolankaya, D. and Barlas, N., (2010) Influence of Vitamin C on Bisphenol A, nonyl- 
phenol and octylphenol induced oxidative damages in liver of male rats. Food and Chemical Toxicology, 48, 2865-2871.

[16] Aydogan, M., Korkmaz, A., Barlas, N. and Kolankaya, D. (2008) The effect of Vitamin C on Bisphenol A, nonylphenol and octylphenol induced brain damages of male rats. Toxicology, 249, 35-39.

[17] Aydogan, M., Korkmaz, A., Barlas, N. and Kolankaya, D. (2010) Prooxidant effect of Vitamin C co-administration with Bisphenol A, nonylphenol, and octylphenol on the reproductive tract of male rats. Drug and Chemical Toxicology, 33, 193-203.

[18] Ilhan, N., Kamanli, A., Ozmerdivenli, R. and Ilhan, N. (2004) Variable effects of exercise intensity on reduced glutathione, thiobarbituric acid reactive substance levels, and glucose concentration. Archives of Medical Research, 35, 294-300. doi:10.1016/j.arcmed.2004.03.006
[19] Wu, M., Xu, H., Shen, Y., Qiu, W. and Yang, M. (2011) Oxidative stress in zebrafish embryos induced by shortterm exposure to Bisphenol A, nonylphenol, and their mixture. Environmental Toxicology and Chemistry, 30, 2335-2341. doi:10.1002/etc.634

[20] Tyl, R.W. (2008) Commentary to the CERHR expert panel report on Bisphenol A. Birth Defects Research B, 83, 152.

[21] Andersen, J.K. (2004) Oxidative stress in neurodegeneration: Cause or consequence. Med, 7, 18-25.

[22] Tyl, R.W., Myers, C.B., Marr, M.C., et al. (2002) Threegeneration reproductive toxicity study of dietary Bisphenol A in CD Sprague-Dawley rats. Toxicological Sciences, 68, 121-146. doi:10.1093/toxsci/68.1.121 